\title{
Toward the Development of a Model for the Adoption of Integration Technologies
}

\author{
Marinos Themistocleous, Khalil Khoumbati and Zahir Irani \\ Information Systems Evaluation and Integration Network Group (ISEing), \\ Department of Information Systems and Computing, Brunel University. \\ Uxbridge, Middlesex, UB8 3PH, U.K.
}

\begin{abstract}
The rapidly changing field of Information Technology has resulted in the development of diverse software applications based on heterogeneous platforms, standards, and architectures. Thus, most organizations confront significant problems with information sharing and business process automation and integration. Since the 1960 s, organizations have deployed various integration technologies, such as Electronic Data Interchange (EDI), Enterprise Application Integration (EAI), and Web Services to piece together their disparate systems. The EDI technology has been explored through the literature, and the main concepts and factors related to its introduction have been analyzed and explained. A need exists to investigate further the adoption of EAI and Web Services. As both technologies are new, the literature on their adoption is limited. In this paper, a comparative analysis of the main adoption models of integration technologies is presented, and common factors are identified and discussed. The authors propose that these common factors can be used as the main constructs of a model that might explain influential factors for the adoption of integration technologies. The proposed model is important as it might explain issues that will possibly affect the introduction of new integration technologies. Thus, the model extends the body of knowledge and contributes toward the development of a theory for the adoption of integration technologies.
\end{abstract}

Reprint requests to: Marinos Themistocleous, Department of Information Systems and Computing, Brunel University, Uxbridge, Middlesex UB8 3PH, U.K.; e-mail: \{Marinos.Themistocleous; Khalil.Khoumbati; Zahir.Irani\}@Brunel.ac.uk 
and Z. Irani

\section{KEYWORDS}

integration technology, adoption model, case study

\section{INTRODUCTION}

During the past decades, enterprises have focused on the latest technological innovations to overcome their organizational problems and to automate their business processes. There was rarely a single approach for implementing information systems (IS) because organizations developed their applications without a common enterprise architectural planning (Markus \& Tanis, 1999). Nowadays dozens, if not hundreds, of different types of open and proprietary systems, each with its own database, networking, and operating systems, exist in organizations (Chalmeta et al., 2001), so that most companies are left with a collection of disparate and/or incompatible systems (Erasala et al., 2002).

Electronic data interchange (EDI) is one of the first technologies used to automate inter-organizational business functions. Many organizations have used EDI to exchange their business documents in an integrated way. Electronic data interchange has evolved as a natural data carrier, replacing paper documents. This approach has enabled organizations to work together, exchanging transaction data in a standard format (Kaefer \& Bendoly, 2000). Business documents are exchanged with trading partners in a nearly paperless environment, with little human intervention (Khazanchi \& Sutton, 2001). Altho'dgh EDI achieves data integration, this technology has not adequately supported tight end-to-end process Business to Business (B2B) relationships (Markus, 2000). The latter causes problems to enterprises because the demand for integrated B2B transactions has increased.

Enterprise Resource Planning (ERP) systems are large, complex software packages developed to carry out much of the back-office processing of organizations. Such systems have been promoted as integrated suites to integrate functions. Although ERP technology is not classified explicitly as one that achieves integration, the authors argue that it can be considered as an integration one. The explanation for this decision relies on the knowledge that ERP systems are integrated suites that internally piece together business process (Davenport, 1998). For this reason, many organizations have turned 
to ERP technology and spent billions of Euros to automate their business processes. Practically, this choice proves that companies have seen ERP systems as a solution to their integration problems.

Enterprise Application Integration (EAI) was introduced as a solution to intra- and inter-organizational systems and process integration, enabling information sharing and business processes, both resulting in efficient operations and flexible delivery of business services to the customer (Erasala, 2002). Enterprise Application Integration can efficiently incorporate custom applications, packaged systems, and e-business solutions into a flexible, manageable infrastructure (Themistocleous \& Irani, 2002). Linthicum (2001) also suggests that EAI provides solutions to intra- and inter-organizational systems.

Web services have emerged as a low-cost alternative for integration, depending on the ability of the organizations to communicate with each other, even if they are using different information systems (Samtani \& Sadhwan, 2002). As a result, almost $56 \%$ of the organizations use web services as part of their EAI projects. Nevertheless, the technology and protocols stack has not evolved sufficiently to allow web services to be used to integrate missioncritical applications, particularly in transaction-heavy environments (Ratnasingam \& Pavlou, 2002).

Such continuous technological innovation in software has enabled the development in integration technologies and promises even easier, cheaper and real time integration solutions. Despite the promise of these solutions to provide enterprise wide systems integration, most organizations continue to struggle with their integration challenges. Yet, much confusion regarding the adoption of integration technologies remains. This paper reviews the literature on the adoption of integration technologies to identify common influential factors. These common factors are then used to build a model that explains the adoption of integration technology. The proposed model in this paper is tested and validated through a real-life case study, with data analysis.

\section{MODELS FOR THE ADOPTION OF INTEGRATION TECHNOLOGIES}

Various models have been proposed in the literature to provide an understanding of the principles behind the adoption of integration technologies innovations. Based on a comprehensive literature review on the 


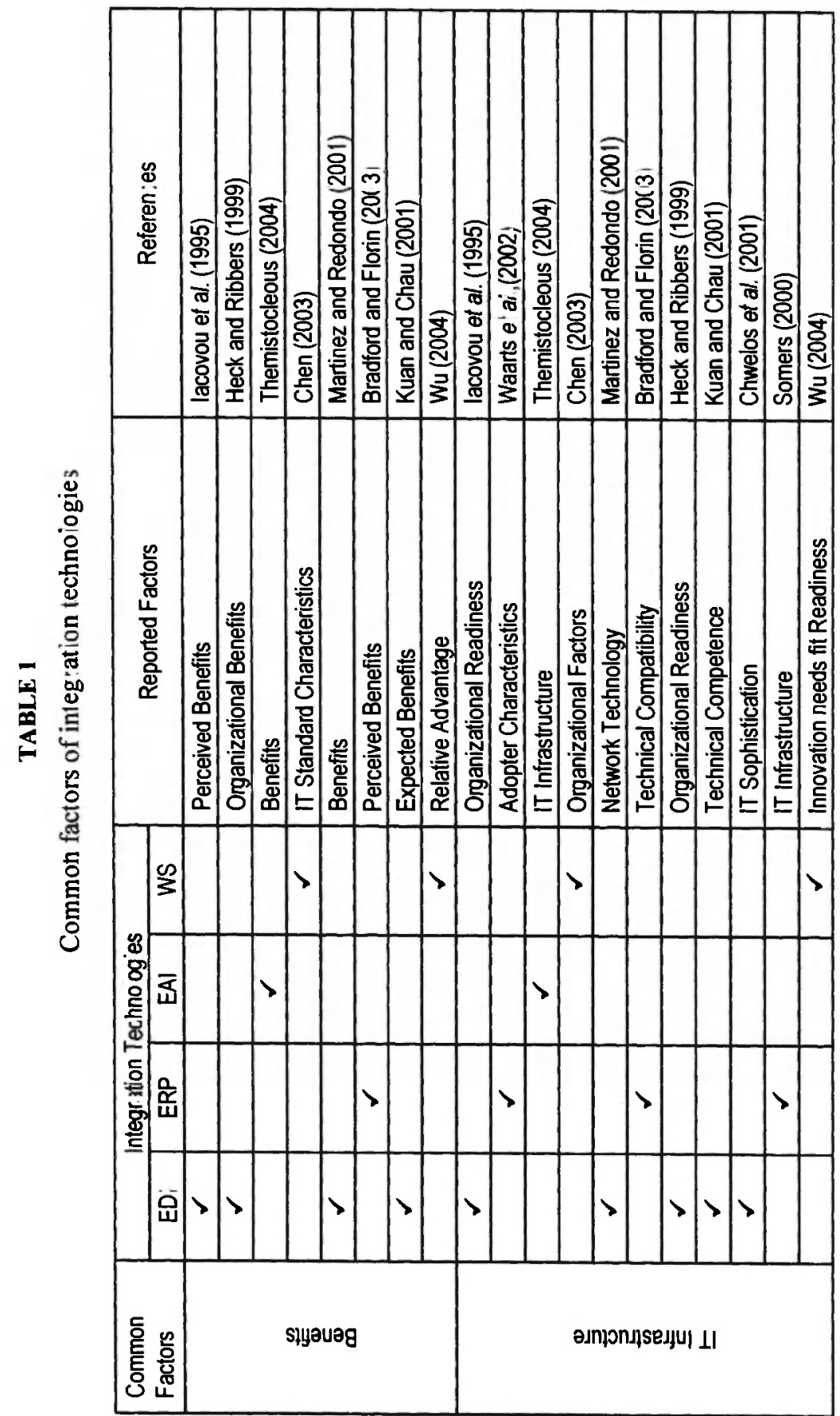




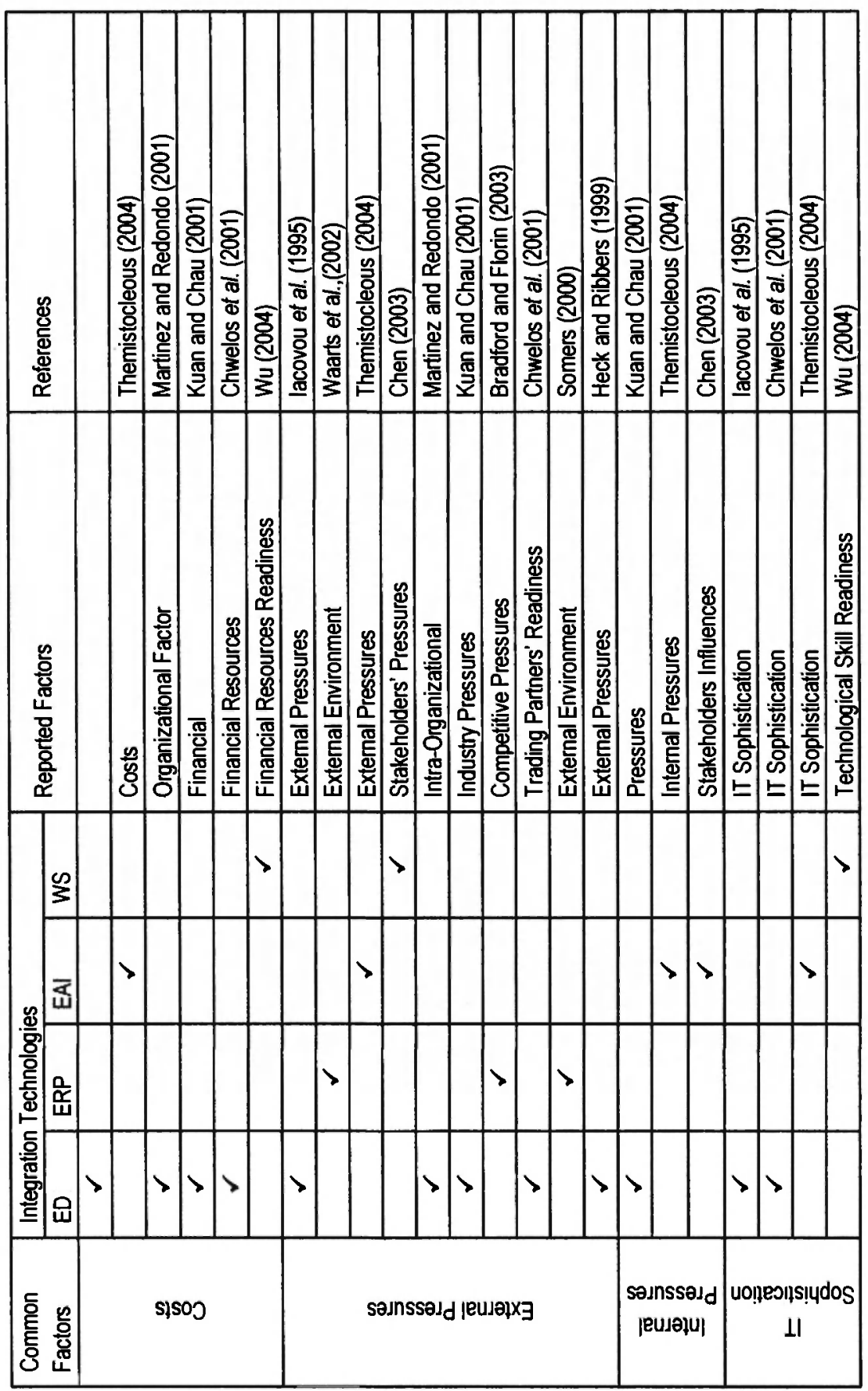


adoption of integration technologies, the authors have reviewed a variety of adoption models.

From the area of EDI, the models proposed by (a) lacovou et al. (1995), (b) Heck \& Ribbers (1999), (c) Chwelos et al. (2001), and (d) Kuan \& Chau (2001) and Martinez and Redondo (2001) are considered for this work. Also from the area of ERP the models of (1) Somers (2000), (2) Waarts et al. (2002) and Bradford and Florin (2003) are used in this paper. Similarly the model of Themistocleous (2004) for EAI adoption and the models of Chen (2003) and Wu (2004) for web services uptake were taken into consideration.

These models report various influential factors for the adoption of these technologies, which were empirically tested in private and public organizations. For the purpose of this, the authors have attempted to analyze these factors and identify the common factors that are being used in all these integration technology adoption models. In doing so, the authors have identified six common factors: (a) Benefits, (b) IT Infrastructure, (c) Costs, (d) External Pressures, and (e) Internal pressures, as illustrated in Table 1 and explained below.

\subsection{Benefits}

Benefits refer to the level of recognition of the advantages that the integration technologies could provide to the organization. Iacovou et al. (1995) in their model of EDI adoption classified perceived benefits into direct and indirect. Direct benefits were mostly operational saving-related (e.g. reduced transaction cost, improved cash flow, reduced inventory levels), and indirect benefits were mostly tactical and competitive advantages that had an impact on business process and relationships (e.g. increased operational efficiency). Martinez and Redondo (2001) reported benefits as a factor in their model of EDI adoption as well, and also categorize the benefits as direct or indirect. The direct benefits include savings in costs in the management of documents. EDI avoids re-keying the data into the computer, the reconciliation of documents, the expense of sending the documents, by mail or fax, and their filing and storage, including the space devoted for this. The indirect benefits include savings in inventories, changes in the activities carried out among the different areas of the firm, and in the redefinition of the 
relationships between suppliers and customers, support to other systems, such as 'Just in Time' and material requirement planning.

Kuan and Chau (2001) adopted benefits as a factor in their model, and reported them as relative advantages. This factor is operationalized as a perceived technological benefit, which refers to the degree of benefits that EDI is providing. Heck and Ribbers (1999) described them as perceived benefits, and their research findings indicate that the benefits that EDI provides forces the small businesses to adopt EDI technology. Similarly, Waarts et al. (2002) represented benefits as an advantage, and it is the subfactor of perceived innovation characteristics. The findings of their research indicate that the organizations consider several technical advantages while taking the decision to adopt ERP, such as reliability, flexibility, scalability and user-friendliness. Bradford and Florin (2003) reported benefits as organizational benefits which include the facilities for integration problems, real-time planning, user satisfaction, and support to quick customer response.

Themistocleous (2004) extended benefits to cover

- operational benefits (e.g. increase productivity, reduce cost and reduce lost sales),

- managerial benefits (e.g. increase performance, improve data quality, and support decision making),

- technical benefits (increase flexibility, reduce redundancy of applications, achieves process integration and results in reliable data),

- strategic benefits ( e.g. achieve customers' stratification and return on investment) and

- organizational benefits (e.g. allow organization to do business effectively).

Chen (2003) reported benefits as relative advantages and categorized this as a subfactor of perceived innovations, which includes such advantages as faster development of the systems, less maintenance, and cost savings. Wu (2004) reported the benefits as relative advantages that web services are supposed to provide to the organizations. Therefore, the above analysis gives sufficient justification to authors to consider the benefits as a common influential factor for the adoption of integration technologies. 


\subsection{IT Infrastructure}

The term IT infrastructure refers to the part of the infrastructure of an organization that forms a platform for the IT applications. This infrastructure consists of the computer systems and the supporting software needed to develop, manage, and operate IT applications, such as operating systems, database management systems, development tools, and management tools. Moreover, Shaw (2000) defines IT infrastructure as the shared IT capabilities that support information flow in an organization. Yet, the nonintegrated nature of this IT infrastructure in organizations causes integration problems, thus raising the need for integration in the organizations. As a result, several authors have reported the IT infrastructure as a factor in their integration technologies adoption models, such as EDI and EAI. Iacovou et al. (1995) referred to IT infrastructure as organizational readiness for the adoption of EDI technology. IT infrastructure is concerned with the level of sophistication of IT uses and IT management in the organization. The authors anticipate that the SMEs with higher technological readiness will be likely to enjoy more benefits from the EDI adoption. Following the Iacovou et al. (1995) model, Heck and Ribbers (1999) reported IT infrastructure as a factor to measure the adoption impact of EDI in Dutch SMEs. The authors also considered this factor as an organizational readiness. Their explanation is that usually SMEs lack the resources that are necessary for EDI adoption. Thus, a low level of computerization makes the integration of EDI systems difficult and necessitates costly expenditure. Kuan and Chau (2001) represent this factor as perceived technical competence, an amount of necessary technical resources that the organization possesses to be able to carry out the course of action in question. Waarts et al. (2002) characterize IT infrastructure as a subfactor of adopter factors, and represent this as IT resources in the organizations. Their research findings indicate that having larger IT resources in the organization for the adoption of ERP does not distinguish between the early adopter and late adopter organizations.

On the other hand, Bradford and Florin (2003) characterize IT infrastructure as technical compatibility. This notion refers to an innovation's compatibility with existing IT infrastructure. IT infrastructure includes the organization's existing software and hardware, which must be integrated with 
the ERP systems. Their research findings indicate that the degree of compatibility of ERP systems with existing IT infrastructure will have a positive relation with successful implementation. Chwelos et al. (2001) adopted it as IT sophistication in the organization. Themistocleous (2004) reported that the nonintegrated IT infrastructure causes many problems, such as technical, strategic and operational, to organizations. Thus, this disadvantage motivates the organization to integrate its existing IT infrastructure. The research finding reported by Themistocleous (2004) implicates the IT infrastructure as an important factor. Furthermore, Themistocleous states that IT infrastructures influence the decision to adopt appropriate EAI solutions. Chen (2003) described the IT infrastructure as a subfactor of organizational factors. Chen states that the standards-based IT infrastructure allows an organization to build information systems that are independent of any specific vendors and technologies. Wu (2004) also reported IT infrastructure as one of the factors for the adoption of web services, and represented it as innovation needs-fit readiness. Wu anticipated that the organizations with diversity of the IT portfolio are positively intent to adopt web services. Thus, the organizations that have a distributed IT infrastructure are more likely to adopt the web service solution. Therefore, Wu represents this as a factor for the adoption of web services. Based on these arguments, the authors consider IT infrastructure as a factor for the adoption of integration technologies.

\subsection{Costs}

A review of integration technologies adoption studies presents costs as an important factor. As a result, Iacovou et al. (1995) reflect this as a financial resource of the organizations for the adoption of EDI. The authors considered this an important factor because previously financial resource has been a hindrance for IT growth in many organizations. Kuan and Chau (2001) reported costs as financial readiness of an organization that has effects on EDI adoption in SMEs and considered it an important factor. Further, they identified several indicators, such as working capital and administrative expenses, to measure the financial readiness of an organization for EDI adoption. Martinez et al. (2001) mentioned costs as a factor for the adoption of EDI technology. The authors have argued that EDI adoption costs are 
dependent on the strategy chosen and on its degree of integration. Themistocleous (2004) reported costs as a factor, categorizing the EAI adoption costs as direct costs, indirect human costs, and indirect organizational costs. Wu (2004) reported cost as a factor and considered it financial resources readiness. In addition, $\mathrm{Wu}$ reports financial resources as an initial cost required for the adoption of Web services. Based on the abovementioned arguments, the authors consider costs as a factor for the adoption of integration technologies.

\subsection{External Pressures}

The term external pressures refers to the influences from the external business environment. Iacovou et al. (1995) reported two main sources of external pressures to adopt EDI technology: (a) competitive pressures and (b) pressures imposed by trading partners. These pressures have been found an important factor for EDI adoption in many other organizations. Thus, Kuan and Chau (2001), following the Iacovou et al. model, adopted external pressures as a factor for EDI adoption, representing them as industry/government pressures. Their findings indicate that the pressures come primarily from the government's plan to terminate all the paper submission of import and export declarations. As a result, this influences organizations to adopt EDi technology. In addition, following the same research trends for EDI adoption, Heck and Ribbers (1999) hypothesize that higher external pressure will lead to greater intent to adopt EDI technology. Martinez and Redondo (2001) represent pressures as organizational pressures. These authors came up with the research finding that external pressures by the supplier and client seem to be a very significant factor for the adoption of EDI by small businesses in the Netherlands. Waarts et al. (2002) reported external pressures as external environment characteristics, which include industry competitiveness and suppliers competition. The results of this research indicate that dependence on parent companies, industry competitiveness, and supply-side activities seem to be more important in influencing the adoption of ERP in the organizations. Bradford and Florin (2003) identified competitive pressures as a factor for the adoption of ERP systems. Furthermore, based on their research results, the authors state that competitive pressures to adopt an ERP system have a 
positive relationship with implementation success. Somers et al. (2001) have reported this factor as an external environment that influences the adoption of ERP in the organizations. Themistocleous (2004) presents external pressures as:

- Increased competition for the increase in productivity

- Pressures from trading partners

- Pressures from trading customers and

- Pressures from suppliers for close collaboration

Therefore, organizations are looking for new practices to better coordination cross- enterprise business processes, which translate into a factor that influences the adoption of EAI. Chen (2003) represents this factor as collaboration with stakeholders', which includes the close collaboration with customers, suppliers and IT product vendors. According to Chen (2003) many SMEs are forced by their major supplier or customers for close collaboration. As a result, many businesses to businesses integration projects are being implemented due to this reason. Therefore, all the above facts provide sufficient justification for considering external pressures as a common influencing factor for the adoption of integration technologies in the organizations.

\subsection{Internal Pressures}

The internal pressures factor has not been widely reported in integration technology adoption models. Kuan and Chau (2001), Themistocleous (2004), and Chen (2003) reported it as an influencing factor for the adoption of the respective integration technologies EDI, EAI, and Web Services. Kuan and Chau did not report internal pressures as an independent factor, but they discussed it in the context of the pressures on IT managers. According to Kuan and Chau, IT managers have pressures from the management to get full utilization and benefits of existing IT resources. Therefore, such pressures lead to the adoption of EDI technology. According to Themistocleous, organizations turned to EAI adoption for many reasons, including technical, managerial, financial, and strategic. Therefore, these reasons present internal pressures for the adoption of EAI. As a result, Themistocleous considered this 
as factor for EAI adoption. Chen represented internal pressures as stakeholder influences for the adoption of web services in the organization. The stakeholder includes the individuals working in the organizations, such as systems integrators. Thus, their influence represents some sort of internal pressures. Therefore, the authors consider the internal pressures as a common influencing factor for the development of the model for the adoption of integration technology.

\subsection{IT Sophistication}

Information technology sophistication is reported as a factor in integration technologies adoption models. The findings of two studies on the adoption of EDI by Iacovou et al. (1995) and Chwelos et al. (2001) report that organizations having sophisticated IT resources will be likely to be adopters of EDI technology. Iacovou et al. (1995), however, have not reported this as an independent factor, but considered this as a dimension of the organizational readiness factor in their model of EDI adoption. In the context of EAI adoption, Themistocleous (2004) reported IT sophistication as a factor in his model, which is due to the level of understanding in addressing technical problems at an enterprise and cross enterprise level. In addition, Wu (2004) also reported IT sophistication as a factor and represented this as technological skills readiness. According to $\mathrm{Wu}$, technological skill readiness is concerned with the level of required knowledge of IT personnel for the adoption of web services. As a result, organizations having higher technological skills will lead to greater intention to adopt web services. Thus, the abovementioned findings provide sufficient justification for considering IT sophistication as a common influencing factor for the adoption of integration technologies in the organizations.

In addition to the integration technologies adoption models, Singletary and Watson (2003) proposed the integration infrastructure theory. Singletary and Watson reported various factors-integration constructs, perceived benefits, environment, motivation, integration decisions, IT infrastructure, costs, and outcomes are represented. As described in Table 2, factors like perceived benefits, environment, motivations, and costs are the same as those reported by 
TABLE 2

Description of factors identified by Singletary and Watson (2003)

\begin{tabular}{|c|c|}
\hline Factors & Description \\
\hline Perceived Benefits & $\begin{array}{l}\text { Perceived benefits are outcomes associated with integration. } \\
\text { Examples: functionality, flexibility, configurability, performance } \\
\text { (efficiency), ease-of-use, human-computer interface and } \\
\text { scalability. }\end{array}$ \\
\hline Integration Decision & $\begin{array}{l}\text { Integration decision is decision to create specific integration } \\
\text { infrastructure, and is similar to technology strategy domain }\end{array}$ \\
\hline Environmental & $\begin{array}{l}\text { Environmental is setting and associated influences that directly } \\
\text { affect perception, decision, operation and outcomes }\end{array}$ \\
\hline Motivations & $\begin{array}{l}\text { Motivations represent the incentives that trigger and provide } \\
\text { impetus for integration infrastructure projects. These include } \\
\text { perceived need, competition, opportunity, available technology, } \\
\text { and pressures (vendors, stakeholders, trends, etc.). }\end{array}$ \\
\hline $\begin{array}{l}\text { Integration } \\
\text { Infrastructure }\end{array}$ & $\begin{array}{l}\text { Integration Infrastructure is set of enabling mechanisms chosen to } \\
\text { facilitate coordination among IT components and between IT and } \\
\text { all areas of organization. }\end{array}$ \\
\hline Costs & $\begin{array}{l}\text { Costs are actual direct and indirect expenditures of money, time } \\
\text { and other resources to create or modify integration infrastructure. }\end{array}$ \\
\hline Outcome & $\begin{array}{l}\text { Outcome is IT services are enabled, created or acquired as a } \\
\text { direct result of integration infrastructure decisions. }\end{array}$ \\
\hline
\end{tabular}

other researchers such as Iacovou et al. (1995), Chwelos et al. (2001), Waarts et al, (2002) and Themistocleous (2004) for the adoption of integration technologies. Thus, these factors support the development of model for the adoption of integration technologies. Singletary and Watson, however, proposed this theory in terms of a model in graphic form, as illustrated in Fig. 1. 


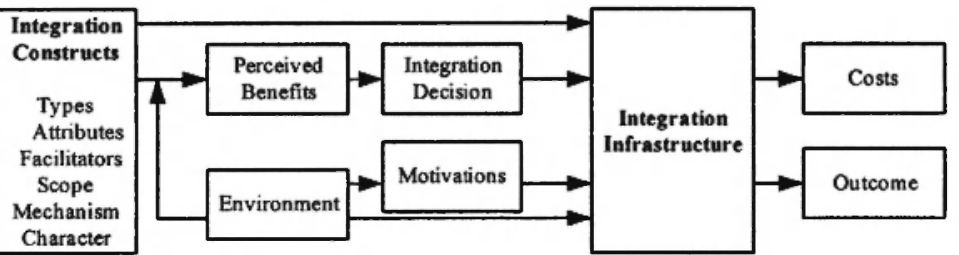

Fig. 1: Information Technology Integration Infrastructure Model (Source: Singletary and Watson, 2003)

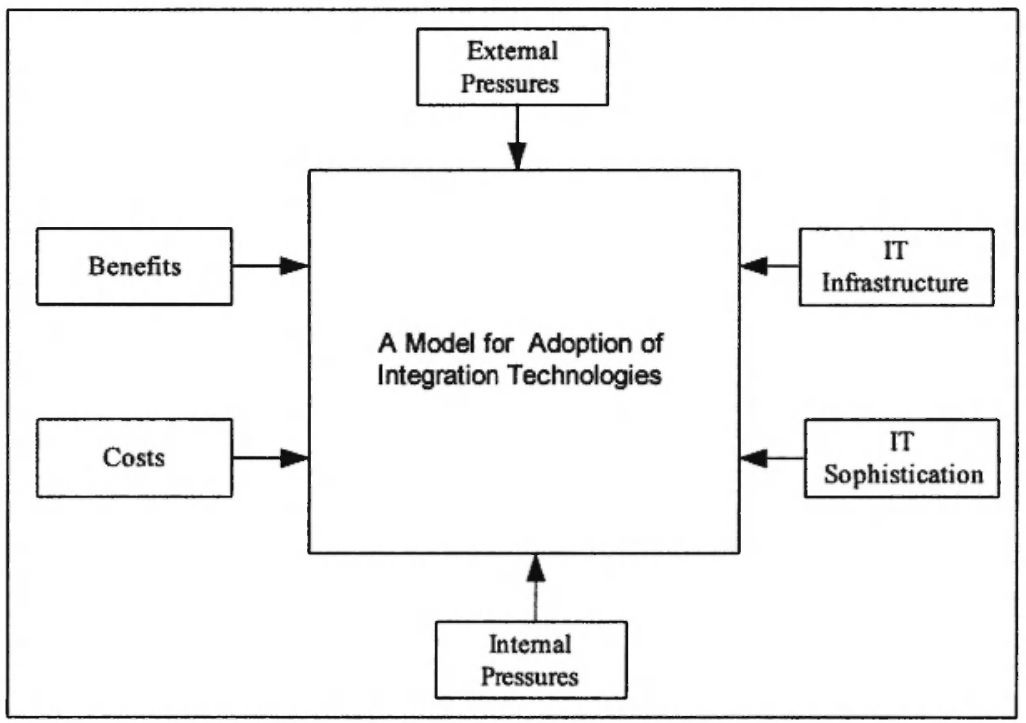

Fig. 2: A Model for Adoption of Integration Technologies

\section{CONCEPTUAL MODEL FOR THE ADOPTION OF INTEGRATION TECHNOLOGY}

In developing a model that explains the main factors influencing the adoption of integration technology, these factors are benefits, costs, IT infrastructure, IT sophistication, internal pressures and external pressures. Each of 
these factors were adopted from previous studies, further, these factors are examined for their suitability for the inclusion in the integration technologies adoption model.

Although the adoption process is acknowledged as varying from organization to organization (Fichman, 1992), we anticipate that the analysis and identification of common influencing factors from the several integration technologies adoption studies could provide broad applicability to most organizations for the adoption of various integration technologies. The reason for this is that as the analysis of the above research covers the broad category of organizations, such as from multinational to SMEs and public sector to private sector organizations. Therefore, the intention for the development of this model is to provide the insight of the common factors that influence the adoption of different integration technologies in various organizations.

Thus, based on the above discussion, the authors propose the common influencing factors model, as illustrated in Fig. 2. This model can be used as the main constructs for the adoption of integration technologies in different types of organizations. The proposed factors can be of significant importance, as they might explain issues that will possibly affect the introduction of integration technologies. Thus, it extends the body of knowledge, and contributes toward the identification of common factors for the adoption of integration technologies.

\section{RESEARCH METHODOLOGY}

To explore these ideas, an interpretive qualitative case study strategy is used for the research in question. In terms of data collection, conducting interviews is considered a primary source, due to reasons such as provision of in-depth information about a particular research issue or question and its recognition as the verbal confirmation or disconfirmation of answers to the questions (Lee, 1991). A predefined interview protocol was used to determine the data needed for the research. Structured and semi-structured interviews were conducted with different peoples from the hospital, i.e. Director of IT services (DIT), Project Manager (PM), Director of Healthcare Business Development (DHB), and several other members of the project team. The 
interviews lasted from 40 to 60 minutes and were on a one-to-one basis. In addition to the interviews, the website of the organization was used for the additional information, such as organizational history and other documents e.g. annual reports. We also used telephone and e-mail to clarify and probe unclear issues that, in some cases, occurred subsequent to transcribing the interviews. To overcome the contradiction associated with data gathering across multiple sources, we crosschecked the data several times. To overcome bias, we employed data triangulation by using the other methods of data collection such as documentation and observation.

\section{CASE DATA AND ANALYSIS}

A case study was undertaken in a hospital to test the conceptual model in the context of EAI adoption. Because the authors cannot generalize the data derived from a single case study, they suggest that the proposed model will allow others to share their experiences to those reported herein. The name of the hospital at which the research was conducted cannot be published due to confidentiality. The authors have adopted a pseudo name WEST-HOSPITAL to refer to this organization. The WEST-HOSPITAL is an acute National Health Services (NHS) trust, established in April 1991, employing more than 3,000 staff across two sites. The trust, along with 72 primary healthcare services providers, provides services to the local population of over 260,000 persons. The main hospital has 638 beds and provides acute healthcare services and the other hospital with 103 beds provides mainly the rehabilitation services. The trust treats over 60,000 in-patients and day cases, approximately 204,000 outpatients, and 70,000 accident and emergency patients each year.

Information for health was the centerpiece of the Labour Party's thinking on IT in the NHS, which identified Electronic Patient Records (EPR) as the key vehicle through which benefits to patients would be driven. This policy document in this regard was the foundation on which all subsequent EPR policies have been built. The document also attempted to map out a progressive path for EPR development, based on the classificatory scheme developed by Brennan and others. There were six levels of electronic record 
development, which Trusts were to achieve such as level 1, i.e. simple Patient Admission System (PAS) and departmental computer systems, level 3, i.e. clinical activity support such as ordering tests and results reporting and Level 6 , i.e. advanced multi-media and Telemedicine. There were the targets for achieving the implementation of EPR systems to level 3 in all NHS trusts by 2005 (U.K. Department of Health, 1998). The local heal th authorities through a Local Implementation Strategy (LIS) will measure the progress in this regard by the NHS trusts.

Following the government directive, the WEST-HOSPITAL formulated its initial local implementation strategy, which described the starting point from where the Borough's healthcare services providers continue to develop and agree on local and coordinated plans that improve the effectiveness of healthcare provision through the use of information and communication technology. Borough healthcare services providers have a long and successful history of working together on IT issues. That collaboration has produced the following benefits:

- national pilot site for new NHS number implementation, the use of a common identifier allowed the development of an integrated patient record across the borough;

- high levels of computerization of primary care practices, $95 \%$ of the 72 practices computerized;

- joint strategy on extension of electronic communications to all primary care practices;

- creation of "super primary care practices" reducing paperwork and using modern technology including telemedicine and diagnostic software; and

- integrated action plans for the Year 2000 issue.

The WEST-HOSPITAL formally adopted electronic health-record development as part of its local implementation strategy for IT and began making the system available to health professionals across the Borough. Nevertheless, a lack of common IT infrastructure emerged throughout the Borough's healthcare and social services providers. Thus, the whole Borough was facing the problem of heterogeneous computing. Traditionally, many systems were departmentalized, which served their individual services without 'talking' to others in general. Only a few systems such as PAS, radiology, and 

and $Z$. Irani

pathology were connected following the point-to-point integration approach.

The introduction of changes increased the pressures for timely, accessible, and up-to-date information from the community and government. Physicians required a fully integrated user front end to create and store electronic patient records, images, and demographics for each procedure and responses to enquiries against individual records available at the click of the mouse. Thus, the local heath authorities realized that the system must provide a fully integrated solution and was required to be integrated with a sophisticated PAS system to get the right information to the right user at the right time with a single patient-data view.

In light of the evolving national strategy, the integration architecture structure was reviewed. The new design intrinsically led to a boundary-free and organization-free patient centric database that could form the basis for a complete community wide electronic record.

The overall aim of the project was to provide clinicians with the information they had requested to improve their ability to provide better care for their patients by ensuring that:

- data on patients is collected once only and shared;

- information is available wherever care is provided;

- all relevant details of care provided by different agencies are brought together on a named patient basis;

- clinicians have the skills and capability of accessing the information available;

- the investment in pre-existing technical infrastructure is fully utilized; and

- the solution should provide integrated views from primary, secondary, and social services.

The IT services department with the help of external consultant worked to examine the available integration solution suitable for the integration problem. In doing so, the IT services department prepared a report based on their integration need and the capabilities of integration technologies. After a thorough discussion, WEST-HOSPITAL took the decision that EAI will be the suitable solution for their problem.

Confusion arose, however, due to a variety of EAI products being available in the market. Therefore, the WEST-HOSPITAL decided to study 
the available EAI products on the market that were specific for healthcare organizations. In doing so, WEST-HOSPITAL evaluated six different EAI products that included:

1. Microsoft's Biz Talk

2. Orion Rhapsody

3. Quovadx cloverleaf

4. SeeBeyond $E^{*}$ Gate

5. Siemens OPENlink and

6. New Era of Networks (NEON) Sybase

To study these EAI products, the hospital did not go through the development of any specific framework that can support them in assessing the integration technologies. Nevertheless, the WEST-HOSPITAL IT services department and external consultant formulated several specific criteria that met the requirements of their integration need. When the interviewees were asked to describe these criteria, they described only the main criteria, such as security, real time integration, support healthcare process integration, customization, and flexibility.

Based on the criteria developed for required integration solution and following the NHS standard Official Journal of the European Community (OJEC) procurement process, an OJEC advertisement was placed, and a number of suppliers were selected to respond to an output based specification. Two vendors were short-listed and Orion systems limited was selected as a project vendor.

The EAI implementation strategy of the hospital consisted of several phases. The first phase lasted from April 2003 through September 2003 and was primarily concerned with the replacement of existing interfacing and systems that included the following:

- introduction of management reporting tools;

- introduction of clinical coding software;

- introduction of case-note tracking;

- replacement of Indigo booked admissions system; and

- interfacing the PAS with existing pathology system, radiology, pharmacy, booked admissions and clinical coding 
The scope of the first phase included supporting a master patient index; patient administration; resource booking, and enterprise-wide scheduling; integrated care pathways; protocol driven requesting and prescribing, and results reporting and clinical noting. Initially, the project was piloted with the integration of 10 different systems, including the equipment data from echocardiograms of WEST-HOSPITAL with the seven primary-care providers and that rolled out to 30 practices across the Borough including two wards of the hospital.

\subsection{IT Infrastructure}

The WEST-HOSPITAL is the host of legacy support systems, such as the patient administration system, laboratory reporting, and pharmacy, radiology, maternity, and child health information systems. Thus, existing IT infrastructure of WEST-HOSPITAL along with the other hospital, 72 primary care providers, and social services department was heterogeneous and consisted of several incompatible systems. Consequently, WEST-HOSPITAL faced significant integration problems while working with the other hospital, primary care providers, insurance agents, and other government bodies. Thus, for WESTHOSPITAL to reconfigure and integrate all the applications that run on the mainframe and the non-mainframe platforms was very difficult. In addition, data and functionality were redundant because many applications stored similar data or ran systems overlapping in functionality. Additionally, the nonintegrated infrastructure caused many problems to the WEST-HOSPITAL because it could not achieve integration. As a result, the hospital could not take the advantage of IT and support closer collaboration with its various stakeholders. Therefore, the existing IT infrastructure represents an influencing factor for the adoption of EAI in the WEST-HOSPITAL. These findings are in accordance with the literature findings such as Iacovou et al. (1995), Heck and Ribbers (1999), Martinez and Redondo (2001), Waarts et al. (2002), Bradford and Florin (2003), and Themistocleous (2004), which represent existing IT infrastructure as a factor for the adoption of different integration technologies. 


\subsection{Benefits}

The interviewees were asked to identify the benefits of EAI, and they agreed that EAI implementation has provided a significant benefit to the hospital. All these benefits have been grouped into five broad categories: operational, managerial, strategic, IT infrastructure, and organizational. These benefits are based on the model developed by Shang and Seddon (2002) for the adoption of enterprise systems, as briefly described below:

- The operational dimension of the benefits includes cost reduction from decreased administrative staffing and resources management. Financial gain is reflected in revenue enhancement from billing practices. Even reductions in lengths of waiting time can be measured in monetary terms and have significant impact on organizational finances.

- The managerial dimension of benefits is achieved through care process advances from better adherence to clinical protocols and improvements in clinical decision-making. Improved quality of patient outcomes through real-time alerts and reduction of medical errors provided through clinical decision support.

- The strategic dimension of the benefits includes improvements in the discharge reporting process, which, in the past, took between 6 and 10 weeks. Now with all of the data availability, the reports are issued within 3 to 7 days of patient discharge. The time saving represents approximately a ten-fold improvement, thus resulting in a better collaboration with stakeholders

- The organizational dimensions of the benefits includes patient satisfaction with improved access to healthcare medical records, decrease in the waiting time, and increasing positive perception of improved quality of care. Immediate access for nurses or physicians enables rapid and informed responses to patients' telephone questions, thus enhancing patient understanding and satisfaction

- The IT infrastructure dimension of the benefits includes the reduction of the number of interfaces and the maintenance time. These findings demonstrate that the use of EAI has reduced the complexity of the interfaces. In addition to that, the use of EAI has resulted in the 
integration of the customs, packages, and e-business applications in a more flexible and manageable way.

All these benefits achieved from the first phase of EAI adoption in the WEST-HOSPITAL represent a major factor for EAI adoption. The benefits further motivated the WEST-HOSPITAL to continue its EAI implements strategy for the remaining phases.

\subsection{Costs}

Initially, interviewees were asked to identify the costs of EAI adoption. They answered that the initial EAI implementation cost was relatively high, but for confidentially reasons did not disclose the actual amount. Nevertheless, the interviewees identified costs includes the following:

- the initial adoption cost,

- costs for maintaining the software (e.g. licenses),

- costs for changing the way people worked including organizational change and training,

- development and consultancy costs, and

- costs for redesigning and changing the clinical processes

To better understand the scope of the costs, the interviewees were asked to give the appropriate rank to the costs following the cost-classification model developed by Irani and Love (2001). The ranking of the costs follows the scale of ranking used by Miles and Huberman (1994), which represents costs less (0), medium $(\theta)$ and high $(\bullet)$. The interviewees ranked all the costs, illustrated in Table 3, associated with the adoption of EAI in the hospital.

As shown in Table 3, all interviewees identified the software costs, communication costs, and consultancy costs as the major direct costs. In addition, hardware and communication costs were reported as less important direct costs for EAI adoption. The most significant indirect costs identified were education cost and training cost of the IT staff, clinicians, and other administrative staff. Moreover, management time, project team time, and external consultant were experienced as significant indirect costs. Maintenance and staff related costs, however, were ranked relatively lower. 
TABLE 3

EAI Adoption Costs in Healthcare Organization

\begin{tabular}{|c|c|c|c|c|}
\hline Category & EAI Costs & DIT & DHB & PM \\
\hline \multirow{5}{*}{$\begin{array}{l}\text { Direct } \\
\text { Costs }\end{array}$} & Hardware costs & o & $\circ$ & $\circ$ \\
\hline & Software costs & $\bullet$ & $\bullet$ & $\bullet$ \\
\hline & Maintenance costs & $\circ$ & $\ominus$ & $\theta$ \\
\hline & Communication costs & $\ominus$ & $\circ$ & $\circ$ \\
\hline & Consultancy costs & $\theta$ & $\bullet$ & $\theta$ \\
\hline \multirow{3}{*}{$\begin{array}{l}\text { Indirect } \\
\text { Human Costs }\end{array}$} & Training costs & $\bullet$ & - & - \\
\hline & Staff related costs & 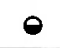 & ○ & $\circ$ \\
\hline & $\begin{array}{l}\text { Time for project team, IT personnel, } \\
\text { external consultant }\end{array}$ & $\bullet$ & $\bullet$ & $\theta$ \\
\hline \multirow{3}{*}{$\begin{array}{l}\text { Indirect } \\
\text { Organizational Costs }\end{array}$} & Resistance to new systems & $\ominus$ & $\circ$ & $\ominus$ \\
\hline & Business process re-engineering & $\ominus$ & $\bullet$ & $\bullet$ \\
\hline & $\begin{array}{l}\text { Costs for the organizations change } \\
\text { management }\end{array}$ & $\ominus$ & $\bullet$ & $\theta$ \\
\hline
\end{tabular}

In interpreting from the empirical data, it appears that the maintenance and staff related costs were considered a significant factor for further implementation of EAI in WEST-HOSPITAL for the remaining phases. This is in coherence with previous literature findings, such as by Themistocleous (2004) and Wu (2004) that show costs as a factor for the adoption of integration technologies.

\subsection{IT Sophistication}

Information technology sophistication is related to the level of understanding and addressing technical problems within the organization. The case study data shows that the level of IT sophistication at WEST-HOSPITAL has affected the adoption of EAI. As reported in the case study, there was a lack of skilled employees to understand integration problems or technologies. As a result, the WEST-HOSPITAL hired the services of the external consultant to 
improve the IT sophistication. Thus, IT sophistication influences as a factor for the adoption of EAI. The case data findings, i.e. IT sophistication is a factor for EAI adoption, confirm the previous literature findings of Chwelos et al. (2001) and Themistocleous (2004).

\subsection{External Pressures}

The empirical data collected from the WEST-HOSPITAL indicates that external pressures represent an influencing factor for the adoption of EAI. In the context of WEST-HOSPITAL, the pressures from government organizations (e.g. NHS) for the provision of better healthcare services to the citizens and partner organizations for improvement in close collaboration represent the external pressures. The pressures from local health authority members, such as primary care services providers and social services providers for the sharing of patients' information, also represent external pressures. In addition, the pressures from citizens for the improvements of healthcare facilities, such as availability of their healthcare records wherever and whenever required to the healthcare services providers for better healthcare, also represent external pressures. All these external pressures influenced the adoption of EAI in WEST-HOSPITAL and represented a decisive factor in EAI adoption. This confirms the previous literature findings that external pressures are a factor for the adoption of different integration technologies such as EDI, EAI, and web services.

\subsection{Internal Pressures}

From the case study findings, it appears that internal pressures such as pressures from the physicians influenced the adoption of EAI in WESTHOSPITAL. The physicians' pressures arose from problems in the provision of better decision making due to non-availability of required timely clinical information, such as laboratory and radiology results. The previous literature findings of Themistocleous (2004) and Chen (2003) also confirm that the internal pressures are an influencing factor in the adoption of integration technologies. 


\section{CONCLUSIONS}

Many organizations use a diversity of information systems to support their organizational and financial business. Yet, such a diversity of heterogeneous and in many cases incompatible systems causes numerous problems. As a result, various integration technologies have emerged to overcome the integration problem.

The introduction of integration technologies requires the organizations to invest heavily in terms of time and money. Thus, there is a need for an integration technology explicit adoption model, which can be as a descriptive framework of reference to aid decision makers to make informative choices when dealing with integration technologies adoption. Therefore, a comprehensive literature review on the adoption of integration technologies was carried out. The authors reviewed a variety of integration technology adoption models and analyzed various factors associated with these models that support the development of a model for the adoption of integration technologies. The authors have identified six common factors: benefits, IT infrastructure, external pressures, costs, IT sophistication, and internal pressures, which are commonly reported in the literature on integration technologies adoption models. Based on these factors, the authors have developed an integration technology adoption model. To test and validate this model empirically, an interpretive and qualitative multiple case study approach was used. The findings from the case study confirmed and validated the proposed conceptual model. Hence, this paper offers an in-depth understanding of the phenomenon of adopting integration technologies. In addition, it provides better support to decision-makers while deciding the adoption of integration technologies in their organizations. Further, it can support the researchers to validate this model in the context of other technologies in different organizations.

\section{REFERENCES}

U.K. Department of Health, NHS Executive. 1998. Information for health-an information strategy for the modern NHS 1998-2005: a national strategy for local implementation, www.dh.gov.uk/PublicationsAndStatistics/Publications/PublicationsLibrary/fs/en 
Bradford, M. and Florin, J. 2003. Examining the role of innovation diffusion factors on the implementation success of enterprise resource planning systems, International Journal of Accounting Information Systems, 4, 205-225.

Chalmeta, R., Campos, C. and Grangel, R. 2001. Reference architecture for enterprise integration, The Journal of Systems and Software, 57, 175-191.

Chen, M. 2003. Factors affecting the adoption and diffusion of XML and web services standards for E-business systems, International Journal of Human Computer Studies, 58, 259-279.

Chwelos, P, Benbast, I. and Dexter, A. 2001. Research report: empirical test of an EDI adoption model, Information Systems Research, 13, 304-321.

Davenport, T. 1998. Putting the enterprise into the enterprise system, Watertown, Massach ussets, USA, Harvard Business School Press.

Erasala, N, David, C. and Rajkumar, M. 2002. Enterprise application integration in the electronic commerce world, Computer Standards and Interfaces, 25, 69-82.

Fichman, R. 1992. Information technology diffusion a review of empirical research, Proceedings of the Thirteenth International Conference on Information Systems, 195-206

Heck, E. and Ribbers, P. 1999. The adoption and impact of EDI in Dutch SME's, Proceedings of the $32^{\text {nd }}$ Hawaii International Conference on System Sciences, CD Proceedings.

Iacovou, C, Benbasat, I. and Dexter, A. 1995. Electronic data interchange and small organizations: adoption and impact of technology, MIS Quarterly, $19,465-485$.

Irani, Z. and Love, P. 2001. The propagation of technology taxonomies for evaluating investments in information systems, Journal of Management Information Systems, 17, 161-177.

Kaefer, F. and Bendoly, E. 2000. The adoption of electronic data interchange: a model and practical tool for managers, Decision Support Systems, 30, 23-32.

Khazanchi, D. and Sutton, S. 2001. Assurance services for business-to-business electronic commerce a framework and implications, Journal of the Association for Information Systems, 1, Article 11.

Kuan, K. and Chau, P. 2001. A perception-based model for EDI adoption in small businesses using a technology-organization-environment framework, Information and Management, 38, 507-521.

Lee, S.A. 1991. Integrating positivist and interpretative approaches to organizational research, Organizational Science, 2, 342-365.

Linthicum, D. 2001. B2B application integration, Reading, Massachusetts, USA, Addison-Wesley.

Markus, M. 2000. Paradigm shifts-E-business and business/systems integration, Communication of the Association for Information Systems, 4, 2-41. 
Markus, L. and Tanis, C. 1999. The enterprise systems experience-from adoption to success, Oklahoma, USA, Pinnaflex Educational Resources.

Martinez, J. and Redondo, Y. 2001. Key variables in the EDI adoption by retail firms, Technovation, 21, 385-394.

Miles, M. and Huberman, A. 1994. Qualitative data analysis: an expanded sourcebook, Newbury Park, California, USA, Sage.

Ratnasingam, P. and Pavlou, P. 2002. The role of web services in business to business electronics commerce, Proceedings of the Eighth Americas Conference on Information Systems, CD-Proceedings, 2239-2243.

Shang, S. and Seddon, P. 2002. Assessing and managing the benefits of enterprise systems: the business manager's perspective, Information Systems Journal, 20, 271-299.

Singletary, L. and Watson, E. 2003. Towards a theory of an IT integration infrastructure, Proceedings of the Ninth Americas Conference on Information Systems, $C D$ Proceedings.

Somers, T, Nelson, K. and Ragowsky, A. 2000. Enterprise resource planning ERP. for the next millennium: development of an integrative framework and implications for research, Proceedings of the Sixth Americas Conference on Information Systems, CD Proceedings, 998-1004

Themistocleous, M. 2004. Justifying the decision for EAI implementations: a validated proposition of influential factors, Journal of Enterprise Information Management, 17, 85-104.

Themistocleous, M. and Irani, Z. 2002. Novel taxonomy for application integration, Benchmarking: an International Journal, 9, 154-165.

Waarts, E, Everdingen, Y. and Hillegersberg, J. 2002. The dynamics of factors effecting the adoption of innovations, Journal of Product Innovation Management, 19, 412-423.

Wu, C. 2004. A readiness model for adopting Web services, Journal of Enterprise Information Management, 17, 363-371. 
